\title{
Clarion call
}

\section{Research scientists and other concerned academics should be more willing to join the climate change debate.}

The Rio+20 conference on sustainable development has ended, but how much has been achieved? The answer in the eyes of many is not a lot. On page 639, Kevin Anderson and Alice Bows make the case that climate scientists and other academics should do more to impress on politicians the urgency for radical action to avert potentially dangerous future climate change over coming decades. Tinkering with the prevailing free-market 'model' to provide incentives for reducing greenhousegas emissions simply won't be enough, they argue, if we are to have any chance of limiting warming to $2{ }^{\circ} \mathrm{C}$ this century. They do not mince their words: "science demonstrates that the threshold of $2^{\circ} \mathrm{C}$ is no longer viable, at least within orthodox political and economic constraints."

Why the urgency? After all, haven't we all heard the argument that economic growth resulting in increased prosperity is itself something of a cure-all for our environmental woes? Wealthier, better educated and more enlightened souls will undoubtedly look after the planet better than humankind has done so far in the industrial era - or so the argument goes. And if all else fails we can depend on future technological fixes. Such attitudes seem naively optimistic, or even dangerously complacent. As Anderson and Bows point out, emissions are cumulative: "What governs future global temperatures and other adverse climate impacts are the emissions from yesterday, today and those released in the next few years."

Today's mitigation efforts are widely regarded within the research community as woefully inadequate. With this in mind, Anderson and Bows urge scientists to overcome their natural reluctance to offer academic judgements - "Liberate the science from the economics, finance and astrology, stand by the conclusions however uncomfortable" - is their clarion call.

This is all the more important given the finding of Karen Akerlof and colleagues (page 648), that information on climate models, for example, rarely appears in US newspapers, and that when models are discussed they are often portrayed as highly uncertain and likely to be inaccurate. The outcome is that a large proportion of the US public have little confidence in, or understanding of, model-based projections of future climate. And yet the communication of climate model science is crucial to policy-making and the wider societal debate regarding mitigation, adaptation and the likely impacts of climate change. The scientific community must therefore ensure that accurate and objectively interpreted information reaches policymakers and the public alike.

The verification and validation of models used to project future climate is crucial, and it is important not to gloss over real uncertainties. One such uncertainty arises from large discrepancies between current reconstructions of twentieth-century tropical Indo-Pacific sea surface temperature (SST) trends. On page 691, Amy Solomon and Matthew Newman report that these discrepancies are largely the result of different estimates of the variability of the El Niño/La Niña-Southern Oscillation in each reconstruction. The implications of this finding for our understanding of Earth's climate system are discussed by Mat Collins in an accompanying article (page 646). He notes that there is a need for better observational data to evaluate the performance of climate models. In addition, Collins highlights the desirability of a detection and attribution study on tropical Pacific SSTs, as well as a thorough investigation of the relationship between historical and future Pacific SST patterns and the underlying mechanisms.

Moving to another matter,

Kevin Anderson expressed his deep scepticism about carbon offsetting as a means of reducing greenhouse-gas emissions (K. Anderson Nature Clim. Change 2, 307; 2012). Donna Green and Liz Minchin (page 641) sympathize with this position but argue that some offsetting schemes have additional benefits beyond their carbonmitigation value. They highlight the highly successful Western Arnhem Land Fire Abatement (WALFA) project in Australia. Arnhem Land is a region of Australia's Northern Territory. It covers an area approaching 100,000 square kilometres about the size of Belgium - and includes the Kakadu National Park located southeast of the territory capital, Darwin. By encouraging traditional land-management practices used over millennia by the indigenous population, the project has achieved a dramatic reduction in greenhouse-gas emissions from bushfires.
The project is effectively funded by the multinational energy giant ConocoPhillips, which pays AU\$1 million per year for the carbon credits generated by WALFA to offset emissions from its Darwin liquid-natural-gas plant. Over the first five years of the project, 707,000 tonnes of emissions from bushfires have been avoided. However, as explained by Green and Minchin, WALFA has also achieved many economic, social and cultural co-benefits, creating jobs and even helping to preserve biodiversity. The project amply demonstrates the value of traditional landmanagement methods when combined with modern scientific understanding.

So successful has it been that WALFA has won two prestigious awards, the Eureka prize for innovative solutions to climate change and the Banksia award, known in Australia as the environmental Oscars. Perhaps more importantly, the project has already inspired at least one similar major initiative in Aurukun in Cape York, North Queensland, bringing significant benefits to the Aboriginal people of the area. However, cynics may reasonably ask how the emissions avoided through WALFA, for example, compare with total emissions from the ConocoPhillips liquid-natural-gas plant in Darwin - including emissions associated with its construction, maintenance and operation, along with the burning of the gas for energy. It would be interesting to know the answer. Remember, it is ultimately the net size of emissions that matters.

Of course, reliable information on carbon dioxide emissions is necessary for keeping track of progress in national mitigation efforts and negotiating future commitments. It will hardly instil confidence, therefore, to learn of a massive discrepancy in China's carbon dioxide inventories (see page 672). The 'gigatonne gap' (actually 1.4 Gt) has been uncovered by Dabo Guan and colleagues whose calculations based on two publicly available official energy datasets failed to match up. The causes and consequences of the discrepancy - larger than Japan's annual carbon dioxide emissions - are further discussed in an accompanying article by Gregg Marland (page 645).

We hope that readers will find plenty of food for thought in this issue of Nature Climate Change, and find other contributions not explicitly mentioned here interesting, relevant and informative. 